\title{
O lado poético da ciência
}

\author{
The poetic side of science
}

Entrevista com

\section{Affonso Romano de Sant'Anna}

Doutor em Literatura Brasileira pela Universidade Federal de Minas Gerais

Entrevista concedida a

\section{Carla Almeida}

(por e-mail em 18.11.2005)

Centro de Estudos do Museu da Vida/Casa de Oswaldo Cruz/ Fiocruz

Av. Brasil 4365, Manguinhos 21045-900 Rio de Janeiro - RJ Brasil

carlalmeida@coc.fiocruz.br
SANT'ANNA, A. R. de: O lado poético da ciência. (Entrevista concedida a Carla Almeida). História, Ciências, Saúde-Manguinhos, v. 13 (suplemento), p. 213-22, outubro 2006.

Nesta entrevista, Affonso Romano de Sant'Anna discorre sobre a sua relação com a ciência e como ela tem influenciado seu trabalho como poeta, cronista e ensaísta. Ele revela uma faceta interessante dessa sua interação com a ciência ao citar alguns poemas que escreveu inspirados em textos sobre ciência. Aborda ainda questões comuns aos processos de criação na literatura e na ciência, lança críticas à arte contemporânea e elogia a disseminação da poesia na Internet.

PALAVRAS-CHAVE: poesia; ciência; poesia e ciência; literatura e ciência.

SANT'ANNA, A. R. de: The poetic side of science.

(Interviewed by Carla Almeida).

História, Ciências, Saúde-Manguinhos,

v. 13 (supplement), p. 213-22, October 2006.

In this interview, Affonso Romano de Sant'Anna talks about his relation to science and how it has influenced his work as a poet, cronista (short-short story writer), and essayist. An interesting facet of his interaction with science is revealed when he cites poems that he wrote under the inspiration of science texts. He addresses issues common to the creative processes in both literature and science, and also voices sharp criticisms of contemporary art while praising the dissemination of poetry on the Internet.

KEYWORDS: poetry; science; poetry and science; literature and science. 
E não me esquecer, ao começar o trabalho, de me preparar para errar. Só quando erro é que saio do que conheço e do que entendo. Se a verdade fosse aquilo que posso entender, terminaria sendo apenas uma verdade pequena, do meu tamanho.

Palavras de Clarice Lispector registradas por Affonso Romano de Sant'Anna no ensaio "O ritual epifânico do texto" (em O que fazer de Ezra Pound?, Ed. Imago).

$\mathrm{O}$ acerto e o erro, o acaso e a intuição são semelhanças recorrentemente apontadas - tanto por artistas como por cientistas no debate sobre as relações entre os processos de produção científica e de criação artística.

Artistas de nacionalidades e áreas diversas têm demonstrado, no entanto, que pode haver uma relação ainda mais estreita entre as manifestações artísticas e científicas.

O poeta, cronista e ensaísta mineiro Affonso Romano de Sant'Anna é um desses artistas. Para ele, "a verdadeira ciência tem tudo a ver com a arte, pois lidamos com o impossível, o que não se pode apreender e se ter à primeira vista".

Sant'Anna se considera um namorado da ciência pois, em vários momentos de seu processo de criação, se vê flertando com ela. "Sou daqueles que pegam um livro científico e técnico e ficam lendo 'distraidamente'. De repente me deparo com a poesia ali contida. Basta reordená-la."

Mas, em alguns de seus trabalhos, o escritor mergulha mais profundamente nas questões científicas. No livro Barroco, do quadrado à elipse, por exemplo, explora, entre diversos aspectos do Barroco, o desenvolvimento e a importância da matemática naquele período. Para tratar desse assunto, Sant'Anna conta nesta entrevista que foi procurar na obra de Kepler a confirmação da análise que propõe no livro, centrada na tensão entre a elipse e o quadrado.

Além de discorrer sobre a relação entre literatura e ciência, criticar a arte contemporânea e elogiar a disseminação da poesia na Internet, Affonso Romano de Sant'Anna fala de seu vício em correlacionar tudo, mesmo os assuntos mais díspares. "Isto está na raiz da arte e da ciência. Na crise do que chamamos 'pósmodernidade', que é o elogio disparado da fragmentação, a leitura interdisciplinar é mais do que necessária."

Você gosta de ciência ou nutre algum interesse especial por ela?

Apesar de ter sido um aluno medíocre de matemática, química e física, foi numa aula de física que fiz um dos meus primeiros poemas, "Poema relativo a Einstein", quando ao saber da morte do 
genial físico, condensei minha emoção naquelas palavras. Quero dizer: tem um lado poético nas ciências que me fascina. Aliás, a verdadeira ciência tem tudo a ver com a arte, pois lidamos com o impossível, o que não se pode apreender e se ter à primeira vista.

\section{Como a ciência e a tecnologia se inserem em seu trabalho artístico?}

Não posso dizer que sou um amante da ciência, mas apenas um namorado. Não tenho physique de rôle para uma relação mais estável. Por isto, volta e meia vou lá e lhe dou uns beijos e abraços. Sou daqueles que pegam um livro científico e técnico e ficam lendo 'distraidamente'. Outro dia, por exemplo, tinha que compor uma mesa-redonda na Uerj [Universidade Estadual do Rio de Janeiro], promovida pelo Departamento de Estudos Judaicos, a respeito da "Intolerância". Poderia ter repetido algo que já tinha pronto - a questão da intolerância dentro da arte de vanguarda no século XX, pois as vanguardas, com a noção de que são donas da verdade e da história, exercem um autoritarismo sobre o sistema artístico. No entanto, me vi pesquisando, por exemplo, a questão da resistência de materiais. Dali a pouco eu estava numa página na Internet, vendo os cursos sobre isto na Unicamp [Universidade Estadual de Campinas], aprendendo sobre cisalhamento, esforço cortante, flexões e deflexões. E comecei a pensar se os engenheiros e os cientistas sociais não poderiam criar modelos para estudar a questão da intolerância, considerada uma pressão social e psicológica. Por que não criar gráficos e modelos que expliquem as revoluções, greves etc.? Vai ver que até existe isto, mas me permiti esse namoro teórico alusivo.

Outro dia estava eu no Chile, convidado a falar poemas em várias cidades, durante o centenário de Neruda. Na cidade de Valdivia, acabei indo à biblioteca da universidade e peguei um livro de astronomia. Comecei a ver gráficos e estudos sobre classificação dos astros, a descrição das galáxias. Eram instigantes, pois iam descre-vendo onde cada uma das estrelas estaria na parte do corpo de uma figura mitológica feminina. De repente, surgiram-me anotações para um poema que está no meu mais recente livro, Vestígios (Ed. Rocco):

\section{Astronomia Amorosa}

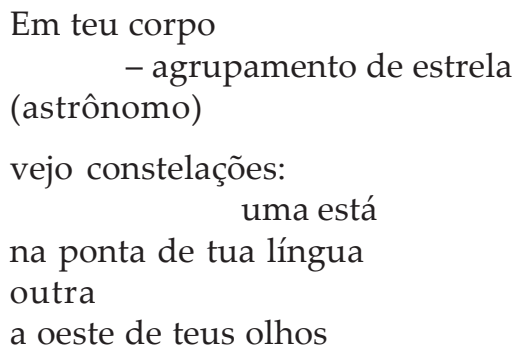


outra

pousada no ombro esquerdo

outra

na curva de tuas nádegas

outra

ao norte do seio se irradia

e na panturrilha esquerda

outra pequena brilha.

No sexo

uma estrela de $5^{\text {a }}$ grandeza

incendeia a galáxia inteira.

Você já disse em entrevistas anteriores que lhe acontece de ler livros científicos como se fossem livros de poesia. Como é isto?

Você vai lendo um livro de ciência e de repente depara com a poesia ali contida. Basta reordená-la. Vou citar dois exemplos, que estão no meu penúltimo livro de poemas, Textamentos. No primeiro poema, uso a técnica da intertextualidade para reordenar um texto tirado de Breve história da ciência - a busca da verdade, do norueguês Eirik Newth:

Aparentemente existe um número infinito de seres vivos que seguem a lei da probabilidade.

$\mathrm{O}$ astrônomo pode calcular onde se encontrará o planeta Júpiter em três mil anos. Mas nenhum biólogo pode prever - onde a borboleta pousará.

O outro poema foi extraído, usando a mesma técnica que, aliás, Manuel Bandeira usou, mas explorando textos de outros poetas. O poema vem de algo que está na p. 151 da História ilustrada da ciência:

Lineu, sábio do século XVIII

Conhecia os pássaros pelo bico

Os peixes pelas nadadeiras

$\mathrm{E}$ os insetos pelas asas.

Procurando Deus

Classificou 5.897 espécies vivas

E ao final da vida anotou:

- Vi as costas do Deus infinito, onisciente e todo-poderoso

Quando ele se foi - e fique tonto. 
É um espanto essa declaração. O cientista ou o artista procurando, procurando esse mistério a que chamamos Deus, e, como ele é tão vertiginoso e perturbador, só o podemos ver à distância ou pelas costas. É que o infinito não cabe na nossa percepção finita. Só nos resta o assombro.

Em sua tese de doutoramento sobre a poesia de Drummond (Drummond, o gauche no tempo), você parte da percepção de que o tempo era variável fundamental em sua obra. O tempo foi variável importante no trabalho de diversos cientistas. Você se aproximou -leu, pesquisou, estudou - de algum cientista que tratou dessa temática?

Andei lendo coisas a respeito, conforme a bibliografia da tese. Livro de [A. J.] Ayer sobre Linguagem, verdade e lógica, livros de divulgação sobre a Teoria da Relatividade, além de Einstein's theory of relativity, de Ernest Cassirer, Albert Einstein: philosopher and scientist, de Hans Reichenbach, o livro de [Frederich James] Crosson e [Kenneth M.] Sayre sobre Filosofia e cibernética, Scott Buchanan sobre Poetry and mathematics etc. Claro que isto tudo se misturava com [Henri] Bergson, [Martin] Heidegger, Parmênides, Heráclito... enfim, a transcendental questão do tempo e do espaço, que levou Novalis a dizer "tempo é espaço interior, espaço é tempo exterior". Há, portanto, um determinado ponto em que a física e a metafísica se articulam como irmãs gêmeas, da mesma maneira que a poesia e a ciência. Por isso sempre incentivei e apreciei aqueles seminários feitos na UFRJ [Universidade Federal do Rio de Janeiro] sobre "Física para poetas", "Química para poetas" etc.

Além de conceitos científicos, você também utilizou a tecnologia em Drummond, o gauche no tempo, aplicando a estilística quantitativa à obra do poeta. Como foi esse trabalho? Você contou com a ajuda de profissionais da área de informática?

Na tese sobre Drummond, depois de ter praticado uma coisa que nos anos 50 chamava-se de 'estilística quantitativa' - ou seja, quantificar certas palavras e expressões de um texto para deduzir suas propriedades - cheguei ao computador. Nos anos 70 o computador ainda era muito pouco inteligente. Só respondia o que eu já sabia. Mas, professores do setor de informática da PUC [Pontifícia Universidade Católica do Rio de Janeiro], Jaime Goldstein e Nelson do Valle e Silva, construíram uns modelos a partir dos meus dados, que ilustram perfeitamente o circuito que o personagem, o alter ego do poeta, a que chamo de personagem 'gauche', faz. Assim, a curva extraída de polinômio de segundo grau ilustra a peripécia metafísica do indivíduo no tempo e no espaço. 
Seguindo esse raciocínio - da utilização da ciência e da tecnologia em sua obra - você diria que tanto uma quanto a outra servem à poesia, ao processo de criação literário? Como se dá esta relação em um sentido mais amplo?

A história da ciência demonstra que muitas descobertas foram feitas num rasgo de intuição. Eu diria queé um momento de epifania, quando a consciência se abre para perceber filigranas que no cotidiano não se observam. A obra de Clarice Lispector que analiso, por exemplo, trabalha inconscientemente a questão da epifania, da revelação, da percepção da 'verdade'. A mesma percepção que Descartes teve e que o levou a escrever o Discours de la méthode. Como ele narra, teve um sonho onde lhe apareciam primeiro um dicionário que seria o "mirabilis scientieae fundamenta" e outro livro que seria o "corpus poetarum" onde a filosofia e a sabedoria se manifestavam conjuntamente.

Outro dia li um depoimento do biólogo brasileiro Alysson Mutuori confessando que foi ao ler as Cartas a um jovem poeta, de Rainer Maria Rilke, que se sentiu motivado a se tornar cientista. Havia naquele livro uma frase que dizia: "A vida agarra-se ao difícil". A partir daí, ele sentiu que tinha que optar por coisas difíceis, pois "se sente mais humano quando busca seus limites".

Quais as principais semelhanças e diferenças entre o processo de produção científica e o processo de criação artístico-literário?

Várias semelhanças. Por exemplo, o 'acaso' faz parte do trabalho científico e da produção artística. Claro que certa tendência dentro da arte contemporânea tem abusado disto, e confunde 'acaso' com 'qualquer coisa', conforme se vê em algumas bienais e galerias e conforme analisei em Desconstruir Duchamp (Ed. Vieira\&Lent). Por exemplo, um cientista jovem brasileiro, Max Langer, especialista em dinossauros, disse que foi graças a "um golpe de sorte" que acabou fazendo a descoberta, em 1998, da saturnalia tupiniquim, um dos quatro dinossauros mais antigos do mundo.

Minha querida Clarice Lispector, na verdade uma filósofa errática, tem uma das mais brilhantes afirmações sobre a questão do erro e do acerto, que poderia ser aplicada à questão da pesquisa. Conforme estudo no texto "O ritual epifânico do texto" (em O que fazer de Ezra Pound?, Ed. Imago), ela tem essas afirmações instigantes:

E não me esquecer, ao começar o trabalho, de me preparar para errar. Não esquecer que o erro muitas vezes se havia tornado o meu caminho. Todas as vezes que não dava certo o que eu pensava ou sentia, é que se fazia enfim uma brecha, e, se antes eu tivesse tido coragem, já teria entrado por ela. Mas eu sempre tivera medo do delírio e erro. Meu erro, no entanto, devia ser o caminho de 
uma verdade: pois só quando erro é que saio do que conheço e do que entendo. Se a 'verdade' fosse aquilo que posso entender, terminaria sendo apenas uma verdade pequena, do meu tamanho.

Agora me recordo que nesse ensaio ["O ritual epifânico do texto"] faço referências também à teoria do caos e à teoria das catástrofes, e cito o matemático e meu amigo Francisco Antonio Doria.

No livro Barroco, do quadrado à elipse, você mostra como algumas descobertas científicas do século XVI foram determinantes para as transformações artísticas. A arte sempre acompanha a ciência ou é a ciência que acompanha a arte?

Veja só. De repente, olha o acaso! Convidam-me a escrever um livro sobre o Barroco. Ora, este é um tema que sempre esteve no meu DNA, pois sou de Minas Gerais e costumava levar meus alunos de Belo Horizonte para ver de perto Ouro Preto, Congonhas e Sabará. Acabei escrevendo dois, um primeiro para atender à encomenda e outro com tudo aquilo que não cabia no primeiro e que levou esse título, Barroco, do quadrado à elipse (Ed. Rocco). Dei-me conta de que, em geral, quando se estuda o Barroco, não se fazem correlações com outros campos. E era necessário fazer essas incursões para se entender melhor as partes e o conjunto. Há uma correlação entre o que sucede em vários campos. Há ideologias e filosofias que aglutinam a percepção, que reelaboram a realidade. Enquanto Heisenberg e Niels Bohr estavam estudando com Einstein a indeterminação, o acaso e a relatividade, várias coisas estavam ocorrendo na pintura, na literatura e no cinema nascente. A arte de vanguarda estava surgindo, colocando tudo em dúvida, mudando a perspectiva, a figuração, procurando o que seria uma espécie de 'antimatéria' e 'anti-arte'. É curioso lembrar que Galileu, por exemplo, andou estudando Orlando furioso, de [Lodovico] Ariosto e Jerusalém libertada, de [Torquato] Tasso. E [Erwin] Panofsky retoma essas considerações entre a literatura e a ciência.

Nesse mesmo livro, você contextualiza e relaciona ciência, música, novela, teatro, moda e gastronomia no período Barroco. Como avalia o estado atual de segmentação dos campos de atividade e conhecimento?

Por uma questão biológica e psicológica, minha cabeça pensa interdisciplinarmente. Tem gente que só pensa fragmentariamente, só se concentra no pequeno, nas partes. Não é defeito, é fatalidade biológica e psicológica. Tenho esse vício de correlacionar as coisas. As coisas mais díspares. E isto está na raiz da arte e da ciência. Afinal, o que é uma metáfora senão a junção de duas coisas improváveis? Um mundo sem metáforas é a morte, a chatice. Por isto, Guimarães Rosa tem aquela imagem linda e profícua, quando fala da 'terceira margem'. E isto que procuramos. Na crise disto 
que chamamos 'pós-modernidade', que é o elogio disparado da fragmentação, a leitura interdisciplinar é mais do que necessária.

Ainda em Barroco, do quadrado à elipse, você relaciona ciência, arte e alquimia. Como estas manifestações se interligavam?

Desde a adolescência eu queria, ao estudar o Barroco, correlacionar as coisas, saber do urbanismo barroco, da gastronomia, da guerra, da ciência barroca etc. E aí, por causa da encomenda daquele livro, me botei lendo e estudando, e foi uma verdadeira revelação descobrir as relações entre a cabala e a ciência - a obra do fenomenal padre Athanasius Kircher - e descobrir que havia até uma matemática barroca. Aí falo de 'matemágica' e refiro-me até indiretamente ao Teorema de Fermat, que surgiu na época barroca e ensandeceu gerações. Tive a sorte de, estando em Roma para pesquisas, poder ver a exposição "Scienza e miracoli nell'ate del 600", que confirmou várias de minhas suposições. A alquimia, no seu delírio místico e metafísico, às vezes faz fronteira com a química e a física. E, como se sabe, o conceito de ciência às vezes é mais ideológico do que científico.

\section{Como a matemática, a princípio tão exata, pode ser mágica?}

Como só acertamos através do erro, para a matemática ser exata, ela lida com o inexato. Outro dia, por causa do centenário da Teoria da Relatividade, andei fazendo até umas aproximações entre a quarta dimensão e a arte. É isto: a realidade nos dá três dimensões, às quais nos acostumamos a perceber, mas a melhor arte e a verdadeira ciência lidam com algo que está noutra dimensão. Então, quando você lê um livro do Kafka, e ele vem com aquelas alegorias do castelo, do monstruoso inseto, do artista na jaula, de repente, nos faz ver algo que não estava visível no dia-a-dia. Desvelamos. Temos uma revelação. Descortinamos um outro plano.

\section{Qual foi a importância da matemática na arte barroca?}

Primeiro é bom lembrar que, desde os gregos (veja os neopitagóricos), a matemática estava em tudo. E quando o Renascimento aflorou, o que se viu foi Miguelangelo, Da Vinci, Brunelleschi e Ghiberti e tantos outros fazendo uso das ciências em suas obras. E com o Barroco não foi muito diferente. O uso da câmera escura, os efeitos da anamorfose e mesmo os cálculos cabalísticos de [Francesco] Borromini para fazer a Igreja das Quatro Fontes, em Roma, mostram isto. Naquele livro, lembro a relação entre a música barroca e a matemática. Não é à toa que já disseram que Bach era uma 'máquina musical'.

O século barroco, para escândalo de muitos, coincide com a busca do 'universo da precisão', não é apenas o século do nebuloso e ininteligível. Tem-se feito uma leitura equivocada do Barroco. 
A leitura da ciência na época é importante para esclarecer esta duplicidade. Pois foi nesse período que as lentes e espelhos tiveram um desenvolvimento tecnológico muito grande. E quando uso as imagens do quadrado e da elipse como base do ensaio, estou tentando aproximar exatamente a intuição e a razão, o mágico e o científico.

Quando a matemática desvenda a mágica, quebra o encanto? Até onde a razão pode ir para não engolir a emoção?

Para mim, ver a estrutura de um poema, a estrutura de um romance, a estrutura de um quadro não me tira a emoção. Soma mais um nível de percepção. Esta coisa de que as análises esfriam a percepção da obra é equívoco romântico. É outro nível, outro plano, outra revelação. Lembro-me quando fiz psicanálise, muita gente dizia ingenuamente: "mas isto não vai tirar a sua inspiração?", "não vai quebrar o encanto da criação?". Ao contrário, só me enriqueceu na vida e na minha obra.

Quando fiz com meus alunos uma série de análises que resultaram no livro Análise estrutural de romances brasileiros, os modelos, os gráficos, as ilações só enriqueceram a percepção. E toda vez que alguém vê uma análise destas redescobre o sentido de um livro de Alencar, Machado ou Graciliano.

Claro que há análises chatas, mas isto diz respeito mais à incapacidade de certas pessoas se expressarem sedutoramente ou à inadequação do objeto de estudo ao sujeito em pauta.

Você cita Kepler como uma das figuras-chave para se entender o período barroco. Vocêestudou profundamente sua obra científica?

Claro que não a estudei 'profundamente', quem sou eu? Fui até onde me interessava e necessitava. Sobre Kepler eu havia visto, por exemplo, algo que está no História ilustrada da ciência, de Colin Ronan, editado pela Universidade de Cambridge. Algo semelhante ocorreu no meu contato com Copérnico. Comprei, numa viagem à Espanha, Sobre las revoluciones, de Copérnico. A mim me interessava ver a presença da elipse, das figuras oblongas, que cosmicamente confirmava o modelo central de minha análise centrada na elipse em oposição/tensão com o quadrado.

Alguns poetas populares brasileiros tratam de temas científicos em suas obras. O cordelista cearense Gonçalo Ferreira da Silva, por exemplo, escreve cordéis sobre grandes personalidades da ciência e da filosofia. Como você vê esse tipo de iniciativa? Ela pode aproximar a ciência da sociedade?

No final do século XIX, houve uma corrente poética, da qual participaram membros da chamada Escola do Recife, que tentou fazer poesia a partir da ciência. Em geral foi um fracasso. Nem uma coisa nem outra. Nem todo mundo tem aquela verve do Augusto 
dos Anjos, que recheou seus textos de palavras científicas e mesmo assim a poesia ainda resultou. No caso destes cordelistas, que são sempre fascinantes, eles estão mais na faixa dos divulgadores, não têm pretensão de fazer obra científica.

Como você vê a poesia, uma das linguagens mais antigas, sendo disseminada pela Internet, um dos avanços mais recentes da tecnologia? Esta seria também uma forma de popularizá-la, de aproximá-la da massa?

A Internet foi uma solução para muitos poetas jovens que vivem isolados. Como se sabe, a poesia é uma espécie de Esperanto, de código secreto, uma língua especial. E houve a junção mágica destas duas coisas: arte e ciência (olha a matemágica, na prática). Os blogs e sites substituem a porta de livraria de ontem e as revistinhas de estreantes. O que ocorre com a arte autêntica é que ela não sucumbe quando surgem suportes novos. Na verdade, amplia seus domínios. 